\title{
Yes, (most) men know what rape is: $A$ mixed-methods investigation into college men's definitions of rape.
}

C) The Author(s) 2020

Not the version of record.

version of record available at:

Psychology of Men and Masculinity,

DOI: $10.1037 /$ men 0000337

\section{Jaclyn A. Siegel' ${ }^{\circ}$, RaeAnn A. Anderson ${ }^{2}{ }^{\circ}$, Kristin E. Silver $^{3}$, and Tara L. Mitchell ${ }^{4}$}

\begin{abstract}
Sexual violence, including rape, is a pervasive problem on college campuses in the United States. Although men perpetrate the majority of sexual violence, men's attitudes, experiences, and perspectives are not typically included in research on rape and sexual violence. We addressed this empirical gap through our mixed-methods analysis of 365 young men's definitions of the term "rape." Our analysis via consensual qualitative research revealed that men's definitions fit into nine primary domains: lack of consent, taken advantage of, sex, sexual activity, unwanted, gender/sex-specific, harm to victim, relationship, and emotional response, as well as a miscellaneous domain. Further, using chi square tests of independence, we compared responses from men with and without a history of sexual violence perpetration. Findings showed that the definitions generated by men with a history of perpetration were less likely to include non-penetrative sexual violence and were more likely to use gender/sexspecific language in their definitions of rape. We conclude that most young men have a generally accurate understanding of rape, though perpetrators' understandings may be somewhat narrower and more limited than those without a history of perpetration. We end with recommendations for refocusing sexual education curricula to better aid in the prevention of sexual violence perpetration. Specifically, given that (most) men know what rape is, educators should emphasize the cultural and situational factors that make rape more likely so all people can reduce the risk of sexual violence and take proactive precautions to prevent it.
\end{abstract}

\section{Keywords}

sexual violence, qualitative research, mixed methods, consensual qualitative research, college men

\footnotetext{
Western University

${ }^{2}$ University of North Dakota, Kent State University

3 University of Akron, Durham VA Medical Center

${ }^{4}$ Lock Haven University
}

Correspondence for this article should be sent to Jaclyn A. Siegel at jsiegel3@uwo.ca. Dr. Anderson's efforts were also supported by a grant from the National Institute on Alcohol Abuse and Alcoholism 5K0IAA026643-02. The content is solely the responsibility of the authors and does not necessarily represent the official views of the funding agency. 
Psychology of Men and Masculinities $X X(X)$

Sexual violence (SV) occurs on a spectrum, with rape representing the most extreme end. At the time of this writing, the United States Department of Justice defines rape as "penetration, no matter how slight, of the vagina or anus with any body part or object, or oral penetration by a sex organ of another person, without the consent of the victim" (United States Department of Justice, $2012)^{5}$. While still fairly narrow, this updated definition was broadened in 2012 to recognize a wider range of sexual activities beyond penilevaginal intercourse that constitute rape. This expanded definition also acknowledges the potential for any person to be victimized by rape, rather than incorrectly implying that men are exclusively the perpetrators. Despite clear definitions set out by lawmaking bodies, researchers and lay people alike tend to provide different definitions of the term "rape" (Haugen et al., 20 I8; Muehlenhard et al., 1992).

While people of any gender can be victimized by rape (e.g., Aosved et al., 20I I; Griswold et al., 2020), men, and college-aged men in particular, comprise the majority of rape perpetrators (Barone et al., 2007; Flood, 2006; Koss, 1993; Ybarra \& Mitchell, 2013). Indeed, in a recent systematic review of 78 independent studies, the average prevalence rate of SV perpetration and rape in a combined sample of 25,524 college-aged men were $29 \%$ and $6 \%$, respectively (Anderson et al., 2019; see also Muehlenhard et al., 2017). Indeed, sexually aggressive strategies are common among college-aged men (Warkentin \& Gidycz, 2007), and research suggests that men of this age group underreport their use of sexual assault strategies (Krebs et al., 2007; Strang \& Peterson, 2017), with some studies suggesting this underreporting is intentional (Strang \& Peterson, 2020). To comprehensively prevent SV, men's attitudes, experiences, and knowledge must be empirically examined; yet, men are often left out of research and conversations about SV (Anderson et al., 2019).
Rather than examining gender differences in college students' definitions of the term (see Haugen et al., 2018), this study exclusively focuses on college-aged men's definitions of rape to develop a better understanding of these men's perceptions and understandings. Further, we explore potential differences in these definitions between men with a history of sexual violence perpetration and those without.

\section{Sexual Scripting Theory and Rape Myths}

One proposed reason why sexual perpetration and violence are common among collegeaged, heterosexual men is due to the sociocultural normativity of these behaviors. Sexual scripting theory (Beres, 2014; Gagnon \& Simon, 1973; Simon \& Gagnon, 2003) is a psychological framework that situates sexual attitudes and behaviors in a social context. The theory proposes that, much like the "script" of a play or movie, "sexual scripts" give individuals directions for how they should act in specific sexual situations. These scripts are perpetuated by a variety of sources including, but not limited to, mainstream media (Kim et al., 2007), magazines (Carpenter, 1998), pornography (Bridges et al., 2016), and music videos (Rodgers \& Hust, 2018). Sexual scripts vary on the cultural, interpersonal, and intrapsychic levels (Gagnon \& Simon, 1973), and college campuses serve as a powerful cultural context for the understanding and enactment of sexual scripts among young adults (Berntson et al., 20l3). While sexual scripts are multifaceted (Morrison et al., 20I5) and differ based on factors such as age, culture, and sexual orientation (e.g., Bowleg et al., 2013; Eaton et al., 20l6), sexual scripts and gender norms are inherently intertwined, as traditional gender roles dictate the options that are perceived as normative and appropriate to individuals in specific sexual contexts (Eaton \& Rose, 20II). For example, in heterosexual sexual relationships, traditional gender-sexual norms specify that men are to be the initiators and pursuers of sex, and women are

\footnotetext{
${ }^{5}$ Prior to 2012, the definition had read, "the carnal knowledge of a female, forcibly and against her will."
} 
to be the gatekeepers and/or passive recipients of men's sexual advances (Byers, 1996; Laner \& Ventrone, 2000). These scripts serve as a powerful cultural force, and aspects of heteronormative sexual scripts have been identified even in nonheterosexual relationships (Hoppe, 201 I; Pham, 2016).

Sexual scripts can normalize violent sexual behavior toward women and can make it difficult for women to actively and firmly say no to unwanted sex (Frith, 20I3; Frith \& Kitzinger, 200 I). Sexual scripts are particularly dangerous when they are laden with rape myths, or false beliefs that place blame on the victims and absolve the perpetrators of SV (Aronowitz et al., 2012; Edwards et al., 20 I I; Ryan, 20 I I). Indeed, endorsement of rape myths (e.g., "women enjoy rape", "rape is an accident", "women lie about being raped", and "women ask to be raped"; Edwards et al., 20I I; McMahon \& Farmer, 20II) is not uncommon among college-aged men (Martinez et al., 20 I8; O'Connor et al., 20 I8; Suarez \& Gadalla, 2010). College-aged men's support for rape myths has been linked to various adverse psychological and behavioral outcomes including hostile attitudes toward women (Chapleau et al., 2007), problematic drinking behaviors (Hayes et al., 2016), adversarial sexual beliefs and acceptance of interpersonal violence (Lonsway \& Fitzgerald, 1995), and various forms of prejudice toward marginalized social groups (Aosved \& Long, 2006).

Further, and important for the current study, rape myths are common in perpetrators' justification for their sexually violent behaviors (e.g., Edwards et al., 20ll). Given the legitimizing power of these myths, debate exists regarding whether men who perpetrate SV recognize their behaviors as violent (Anderson et al., 2019; Koss, 1998; Snyder \& Higgins, 1988), and some have suggested that this discrepancy may reflect men's lack of understanding of the definition of rape (Edwards et al., 2014). For example, in a qualitative study assessing convicted sex offenders' motivations for their sexually violent behavior (Beech et al., 2006), rather than perceiving their behaviors as internally and personally-motivated, perpetrators attributed their sexually violent behaviors to five implicit theories: a belief that the world is dangerous and men are hostile, a belief that women are dangerous and evil, a perception of women as sexual objects to be violated at will, a perceived uncontrollable male sex drive that cannot be reasonably contained, and entitlement to whatever they would like. Further, in a recent content analysis of 68 anonymous narratives from sexual assault perpetrators taken from the social media website Reddit, a majority of responses used rape-normalizing sexual scripts to explain their behaviors (Hipp et al., 2017). Much like the convicted sex offenders, some posts suggested the perpetrators coerced their partners using gender-stereotyped sexual scripts, (e.g., "I had this impression that girls didn't want to be seen as sluts or whores so they would pretend that they didn't want to have sex when really they did") or denied their partners' resistance when sexual activity was initiated. Others engaged in victim blame and hostility, attributed their behaviors to hormones, or described their victims as objects or less than human to justify their behaviors. While research suggests that the sexual scripts of perpetrators may be warped by rape myths, it remains unclear whether rape myths are fundamental components of college-aged men's definitions of rape, particularly those who have no prior history of SV perpetration.

\section{Current Study}

Taken together, these findings indicate a need to examine college-aged men's basic understandings of rape to examine, in an openended manner, to what degree they are influenced by sexual scripts and rape myths. In the present study, we provided college-aged men -with and without past histories of SV perpetration -- the opportunity to freely provide definitions of the word "rape" to explore the extent to which rape myths and sexual scripts are embedded in these men's basic definitions of the term. We chose a qualitative paradigm to allow for inductive analysis of men's definitions, given the paucity of research on this topic, followed by a quantitative approach, which allowed us to 
Psychology of Men and Masculinities $X X(X)$

make meaningful distinctions between men with and without a history of SV perpetration.

\section{Method}

\section{Participants and Procedure}

In total, 488 college men recruited from the Psychology undergraduate participant pool at a large, public university in the Great Lakes region participated in the study. Data were coded to saturation, meaning that we did not anticipate that we could extract new domains in future results (Williams \& Hill, 2012). The final sample consisted of responses from 365 male students $($ Mage $=19.88, S D=4.56)$. Most participants were Caucasian or White $(n=305 ; 83.6 \%)$, with others identifying as Afri- can American $(n=29$; 7.9\%), Asian American (n

$=12 ; 3.3 \%$ ), Native American ( $n=7 ; 1.9 \%)$, or that their racial group was not listed in the choices provided $(n=26 ; 7.2 \%)$. Participants primarily identified as heterosexual or straight $(n=$ $319 ; 86.2 \%)$, gay $(n=20 ; 5.5 \%)$, bisexual $(n=19$; $5.2 \%)$, asexual $(n=2 ; 0.5 \%)$, demisexual $(n=1$; $0.3 \%)$, heteroflexible $(n=1 ; 0.3 \%)$, or did not provide a response $(n=3 ; 0.8 \%)$. The demographic composition of this sample was consistent with the university as a whole. A majority of the sample was sexually ac- tive $(n=218 ; 59.7 \%)$. Two hundred and one par- ticipants (55.1\%) identified as single, with others indicating that they were single but dating $(n=58 ; 15.9 \%)$, in a committed relationship ( $n=99 ; 27.1 \%)$, engaged or married ( $n=4 ; 1.10 \%)$, or did not provide a response $(n=3 ; 0.8 \%)$. Based on scores acquired from combining scores on two measures of sexual perpetration history (see below), I 40 participants (38.4\%) were included in the perpetrator category.

Ethics approval was granted from Kent State University. Participants were recruited through an undergraduate psychology participant pool at a large, midwestern university. To be eligible, par- ticipants needed to identify as male and as stu- dents. The entire study took place online. Eligible participants were directed to a Qualtrics survey where they provided their informed consent. As part of a larger study, participants responded to several questionnaires related to sexual violence, which were presented in a counterbalanced order. Participants were debriefed via survey on their distress and perceived benefits of participation, and were compensated with one course credit toward the completion of a psychology course. No monetary compensation was provided.

\section{Materials}

Aside from the main prompt in question (i.e., "There are several activities that are considered sexual assault, one of which is rape. How would you define rape?"), two measures were administered to each participant, which, when combined, identified if they had a history of SV perpetration. Two different measures were employed and combined because past literature indicates that some men under-identify certain types of sexual perpetration (Krebs et al., 2007; Strang \& Peterson, 2017, 2020).

Sexual Experiences. The Sexual Experiences Survey - Short Form Perpetration (SESSFP; Koss et al., 2007) contains 35 items describing seven sexual behaviors (e.g., vaginal sex, oral sex, unwanted touching) and five potential tactics for initiating each of these behaviors (verbal criticism, verbal pressure, alcohol incapacitation, threats of sexual force, and physical force). Participants read the following prompt before completing items, "These are questions about things you have done to someone else since the age of 14." Participants responded "yes" or "no" to indicate whether they had ever engaged in the behavior. Past research has established the convergent validity of the SES-SFP in samples of collegeaged men (Anderson et al., 20l7; Johnson et al., 2017).

Conflict Tactics. The Revised Conflict Tactics Scale-2 (CTS-2; Straus et al., 1996) consists of two parts, perpetration and victimization. Each section contains 39 items that measure how often people have used or been subjected to physical and psychological strategies to negotiate 
conflicts with their partners since the age of 14 . The measure consists of five subscales: Negotiation, Psychological Aggression, Physical Assault, Sexual Coercion, and Injury. For the purposes of this study, only the Sexual Coercion subscale was measured (e.g., "used force to make partner have sex", "used threats to make partner have anal sex"). The CTS-2 and its subscales have demonstrated good validity in samples of college aged students (Anderson et al., 2017; Straus et al., 1996).

\section{Analysis}

Qualitative data were analyzed using Consensual Qualitative Research-Modified (CQR-M; Spangler et al., 20I2), an analytic method for analyzing short and straight-forward qualitative data. The modified version of CQR was employed to account for the large amount of data provided and the brevity of each individual data piece. CQR-M is a rigorous, replicable, inductive methodology whereby independent raters establish a coding scheme by consensus (Hill et al., 2005). In CQR-M, independent raters engage in triangulation through ongoing discussion to find shared meaning in responses (Spangler et al., 20I2).

By its very nature, $C Q R$ is "constructivist, with a hint of postpositivism" (Hill et al., 2005, p. 197). Researchers working within a CQR framework recognize knowledge as socially situated, arising out of learned and understood meaning, rather than rote memorization. Therefore, we did not anticipate that participants would respond with textbook definitions of terms or complete and objective answers. Rather, we assessed consistent domains within men's conceptual and schematic definitions of rape to analyze the types of information that is regarded as sufficient and necessary for defining the term. We maintained reflexivity throughout the process (Hill, 20I2), searching for instances where our thinking may be influenced by our own experiences, consulting with other members of the research team to increase transparency, and arriving at consensual conclusions.

It is important to note that the social locations of the research team can influence the ways that data are collected, analyzed, and presented
(Yeh \& Inman, 2007); our analysis is situated within the context of our identities as researchers. The coding team consisted of four undergraduate research assistants, who varied in gender, race, and history of victimization. Coders were supervised and moderated by a PhD student in psychology who identifies as a radical feminist, Jewish, cisgender woman. This was the first coding experience for the four undergraduate researchers, although the supervisor of the team had expertise in both SV research and CQR-M methodology. The entire project was overseen by a White, cisgender professor of psychology, who had extensive knowledge of the research surrounding SV perpetration. To reduce the likelihood of within-team bias and increase trustworthiness (Williams \& Hill, 20I2), the data and coding scheme were sent to an outside researcher (PhD candidate, feminist, White, cisgender woman, no sexual assault experience), who recommended clarifications and minor revisions to the coding.

Initially, the project supervisor generated a list of domains, or broad categories of repeated ideas extracted from the research data, relevant to the project and created a codebook with operational definitions of the domains, which was provided to the research assistants. The initial domains included: Lack of consent, sexual activity, sex, taken advantage of, unwanted, harm to victim, gender/sex-specific, relationship, emotional response, multiple people, crime, reasons for rape, age of victim, fear, and shared responsibility. Based on low frequency, reasons for rape, age of victim, fear, and shared responsibility were then grouped together into a miscellaneous domain.

The coders read the responses and voted on the codes by consensus after independently reviewing the data and taking notes. In some cases, additional, noteworthy variant domains and subdomains (e.g., reasons for rape - dominance, reasons for rape - pleasure) were extracted. We allowed for any individual response to fit into several domains, given that they varied in length and complexity. 


\section{Results}

Overall, the analysis revealed nine primary domains (lack of consent, taken advantage of, sex, sexual activity, unwanted, gender/sex-specific, harm to victim, relationship, emotional response) and a miscellaneous domain for notable variant domains (see Table I for frequencies and exemplary quotes) We conducted exploratory analyses to assess differences between individuals who reported lifetime experiences of SV perpetration and those who did not (see Table 2). Given the spirit of qualitative research is hypothesis-generating and exploratory, we did not make specific predictions about the domains men with perpetration histories might provide.

\section{Consensual Qualitative Analysis}

Lack of consent. Lack of consent was defined as "at least one person in the encounter does not or cannot agree or give permission for the action." Most responses were explicit that the behavior was "unauthorized", or that consent was not granted by at least one member of the encounter. Responses could be categorized as ignoring verbal commands, ignoring nonverbal cues, and incapacitated. Ignoring verbal commands was defined as "perpetrator of the act disregards spoken demands to stop." Responses in this subdomain included the victim stating that they did not want to engage in the encounter, such as by saying "no," "stop," or that they felt uncomfortable. Ignoring nonverbal cues was defined as "perpetrator of the act disregards physical demands to stop made before and/or during the act". Some examples of nonverbal cues included "signs," "struggle," "laying hands out," or "fighting you." Several responses indicated that sexual activity with someone that "could not provide consent to sexual activity due to incapacitation" constituted rape. Examples of incapacitation included being "passed out," "black out drunk," "not in the (state of) mind," "under the influence," "messed up," or "intoxicated."
Taken advantage of. A majority also indicated that rape involves taking advantage of another person, which was defined as "employing a tactic to make someone engage in sexual activity who is unwilling." Most responses in this subdomain could be further categorized into force, manipulation, or drugged. Responses were coded into the force category if they indicated that rape included "exerting physical strength onto someone" (e.g., "keeping someone bound/held down" and "forcing [oneself] onto another individual"). Manipulation was defined as "mentally/verbally coercing the victim into a sexual act," and responses included "pressure," "influence," "disregard," and emotional or verbal manipulation. When participants mentioned the use of "substances to alter the victim's state of consciousness," responses were classified into the drugged subcategory. Responses were included in this category if the drugs or "substances" were used to disarm the victim.

Sex. Many explicitly noted that "the act of [penile] penetration (i.e., oral, vaginal, anal, intercourse)" must occur for the encounter to constitute as rape, a domain we labeled as sex. Specifically, responses in this category referred to "sex," "intercourse," or "penetration."

Sexual activity. Others indicated that rape included "any physical or sexual act done to another person (that does not include penetration; i.e., groping, kissing, touching genitals)". Examples of "sexual activity" included "sexual act(s)" or "actions," "sexual advances," "sexual relations," "sexual touching," or "sexual anything."

Unwanted. Some mentioned that rape is unwanted, which was defined as "at least one person in the encounter lacks desire for the action." While similar to lack of consent, we differentiated between the two categories in our analysis because sex can technically be unwanted but consensual or nonconsensual but "wanted" (Impett \& Peplau, 2002; Peterson \& Muehlenhard, 2007). 
Table I.

Chart of Domains, Subdomains, and Examples

\begin{tabular}{|c|c|c|c|}
\hline Domain & $\begin{array}{l}\text { Sub- } \\
\text { Domain }\end{array}$ & $\begin{array}{l}\text { Preva- } \\
\text { lence }\end{array}$ & $\begin{array}{c}\text { Example } \\
\text { (Additional labels) }\end{array}$ \\
\hline \multirow[t]{4}{*}{ Lack of Consent } & & $\begin{array}{l}233,63.84 \% \\
\text { Typical }\end{array}$ & $\begin{array}{l}\text { "Forcibly having sex or sexual acts with someone without there } \\
\text { [sic] proper permission" } \\
\text { (Sex, Sexual Activity, Taken Advantage of - Force) }\end{array}$ \\
\hline & $\begin{array}{l}\text { Ignoring Ver- } \\
\text { bal Com- } \\
\text { mands }\end{array}$ & $\begin{array}{l}36,9.86 \% \\
\text { Variant }\end{array}$ & $\begin{array}{l}\text { "Forcing sexual activity on someone who has verbally said no" } \\
\text { (Sexual Activity, Taken Advantage of - Force) }\end{array}$ \\
\hline & $\begin{array}{l}\text { Ignoring } \\
\text { Nonverbal }\end{array}$ & $\begin{array}{l}13,3.56 \% \\
\text { Variant }\end{array}$ & $\begin{array}{l}\text { "The victim does not give consent, is fighting you and you con- } \\
\text { tinue to make moves, is screaming NO or STOP" }\end{array}$ \\
\hline & Cues & & (Lack of Consent - Ignoring Verbal Cues) \\
\hline \multirow[t]{5}{*}{ Taken Advantage of } & & $\begin{array}{l}216,59.18 \% \\
\text { Variant }\end{array}$ & $\begin{array}{l}\text { "Unwanted/unwilling sexual acts; Any sexual activity against } \\
\text { somebody's will" } \\
\text { (Unwanted, Taken Advantage of) }\end{array}$ \\
\hline & Force & $\begin{array}{l}154,42.19 \% \\
\text { Variant }\end{array}$ & $\begin{array}{l}\text { "Forcing a sexual act on someone who does not give consent; } \\
\text { Keeping someone bound/held down with intent of committing a } \\
\text { sexual act" } \\
\text { (Taken Advantage of - Force, Sexual Activity) }\end{array}$ \\
\hline & Manipulation & $\begin{array}{l}8,2.16 \% \\
\text { Variant }\end{array}$ & $\begin{array}{l}\text { "Any way you'd take advantage of a fellow human weather [sic] it } \\
\text { be through pressure, influence, or disregard" }\end{array}$ \\
\hline & Drugged & $\begin{array}{l}7,1.89 \% \\
\text { Variant }\end{array}$ & $\begin{array}{l}\text { "Using some kind of force or method (drugging for example) to } \\
\text { prevent the victim from preventing the perp from penetrating the } \\
\text { victim vaginally, anally or orally" } \\
\text { (Taken Advantage of - Force, Sex) }\end{array}$ \\
\hline & Incapacitated & $\begin{array}{l}30,8.22 \% \\
\text { Variant }\end{array}$ & $\begin{array}{l}\text { "Rape is taking advantage of someone without their consent. } \\
\text { Such as a girl that is too drunk to walk or function. If the girl or } \\
\text { guy is blacked out drunk and you par take in sexual activity with } \\
\text { them then that is rape" } \\
\text { (Lack of Consent, Gender/Sex-Specific, Sexual Activity) }\end{array}$ \\
\hline Sex & & $\begin{array}{l}176,48.22 \% \\
\text { Variant }\end{array}$ & $\begin{array}{l}\text { "Any form of penetration with an instrument, object, with a pe- } \\
\text { nis" }\end{array}$ \\
\hline Sexual Activity & & $\begin{array}{l}154,42.19 \% \\
\text { Variant }\end{array}$ & $\begin{array}{l}\text { "Sexually touching another person without their consent" } \\
\text { (Lack of Consent) }\end{array}$ \\
\hline Unwanted & & $\begin{array}{l}98,26.85 \% \\
\text { Variant }\end{array}$ & $\begin{array}{l}\text { "Having a form of sex with someone without them wanting you } \\
\text { to" } \\
\text { (Unwanted, Sex) }\end{array}$ \\
\hline Harm to Victim & & $\begin{array}{l}23,6.30 \% \\
\text { Variant }\end{array}$ & $\begin{array}{l}\text { "Forcing yourself upon/inside an individual, abusing" } \\
\text { (Sex, Taken Advantage of - Force) }\end{array}$ \\
\hline
\end{tabular}




Fear
Gender/Sex-Specific
Relationship
Erime
Sponse
Multiple People

$\begin{array}{ll}\text { Emotional } & 7,1.92 \% \\ \text { Harm } & \text { Variant }\end{array}$

Physical

Harm

$12,3.29 \%$

Variant

$20,5.48 \%$

Variant

9, $2.47 \%$

Variant

6. $1.64 \%$

Variant

5, $1.37 \%$

Variant

5, I. $37 \%$

Variant

Dominance

$2,0.55 \%$

Variant

Pleasure

$2,0.55 \%$

$2,0.55 \%$

Variant

I, $0.27 \%$

Variant
"Rape is when someone takes advantage of another individual sexually, robbing the person of their self-esteem and taking away something that was not theirs to take"

(Taken Advantage of, Sexual Activity, Emotional Response, Emotional Harm)

"Physically injuring and forcing a female who has said no to participate in sexual activity" (Gender/Sex-Specific, Taken Advantage of - Force, Lack of Consent - Ignoring Verbal Cues, Sexual Activity)

"A man forcing a women to engage in any sexual activity such as sex or even contact with either party's genitals" (Sexual activity, Sex, Taken Advantage of - Force)

"Rape is when on [sic] partner forces their partner to have sex with them"

(Sex, Taken Advantage of - Force)

"One of the most disgusting and degrading things you can do to a female"

(Gender/Sex-Specific)

"Rape is when someone or when a group of people force someone to have sexual activity without their consent" (Taken Advantage of - Force, Lack of Consent, Sexual Activity)

"Rape; a crime that is committed to a person that does not give consent to sexual activities but is forced into them" (Lack of Consent, Sexual Activity, Taken Advantage of - Force)

"Forcing women or men to follow your command"

(Taken Advantage of - Force)

"To me, rape is one person gaining sexual satisfaction from another person without that person's consent or knowledge of the sexual act taking place"

(Sexual Activity, Lack of Consent)

"Unlawful sexual activity and usually sexual intercourse carried out forcibly or under threat of injury against the will usually of a female or with a person who is beneath a certain age or incapable of valid consent-compare sexual assault, statutory rape" (Crime, Sexual Activity, Sex, Taken Advantage of - Force, Gender/SexSpecific, Lack of Consent, Harm to Victim - Physical, Harm to Victim Emotional)

"When a party doesn't agree to by own accord [sic] or doesn't feel safe with the partner, yet insertion occurs"

(Lack of Consent, Sex, Relationship, Fear) 
Shared Responsibil-

ity
I, $0.27 \%$

Variant
"I would define rape as forced sexual intercourse with someone who does not want to have it. If someone is passed out and is unconscious it is morally wrong. If the victim is intoxicated they should be held responsible for their actions as well as aware of their actions be held partially responsible for the accident" (Unwanted, Taken Advantage Of - Force, Sex, Incapacitated, Victim)

Note. The final counts were tabulated and labelled as general (nearly all), typical (more than $50 \%$ ) or variant (less than $50 \%$ ) on the basis of frequency (Hill et al., 2005). Domains with an extremely small number of responses $(\leq 5)$ were grouped into a miscellaneous category (Hill et al., 2005). Although Hill et al. (2005) suggest that, in samples larger than I5, only domains with one response should be included in the miscellaneous section, due to the large sample size in this study, we chose to expand this to five or fewer responses. Most responses were categorized into two or more domains, as noted by the additional domains listed under each quote.

Responses in this domain sometimes noted that the other person "did not want it" or that it was "unwanted."

Harm to victim. Other responses were categorized as harm to victim. Answers fit into this category if they indicated that there was any form of harm to the victim as a result of the incident. Some responses were broad and general, suggesting that rape involved any form of harm to the victim, such as "abuse." Others specified physical versus emotional harm. Some indicated that rape in volves physical harm, or "bodily injury to the victim." Physical harm responses included the use of "brutality" or "violence," causing "injury," or "hurting" the other person. Some participants observed that rape involved emotional harm, which was defined as mental or psychological trauma to the victim. Examples of emotional harm included "robbing the person of their self-esteem" and "humiliat[ion]." Notably, with only one exception, every response that was characterized as emotional harm also mentioned physical harm.

Gender/sex-specific. Several participants provided responses that were categorized as gender/sex-specific if their definition mentioned the perpetrator or victim is male or female. Gender/sex-specific responses unilaterally described men, males, or people with penises as the perpetrators while girls, women, females, or people with vaginas were described as the victims.

Relationship. A few responses were categorized into the relationship domain, particularly if the response implied that "the sexual act happens with a partner or significant other." Relationship responses included phrases such as "partners," and "member[s] of sexual relationship[s]."
Emotional response. Some provided emotional responses to the question. Responses were categorized into this domain when the answer suggested that "an intense feeling was evoked from the respondent." Responses with strong emotions attached sometimes referred to rape as "childish," "immature," "horrible," and "a sick, disgusting act."

Miscellaneous. Some responses were endorsed infrequently, though their inclusion was noteworthy. For example, some responses were categorized as multiple people, if they "mentioned more than one person committing or receiving the act." Answers in this domain referred to "groups" or "one or more people." Responses were categorized as crime if they used legal terms in their definition, describing rape as being against the law. Responses were categorized into the crime subdomain when the respondent recognized the act is criminal in nature. Answers included those with phrases such as "crime" or "unlawful." A few responses were categorized into the reasons for rape domain because they made explicit mention of "why the perpetrator commits the sexual act." These responses were categorized as dominance (e.g., "want to feel dominant," and "follow [ing] your command") or pleasure (perpetrator performs the act to feel sexual satisfaction or forces the other person to "please" them). Two responses included the age of the victim. Specifically, these answers indicated that victims were under 18 years old. One response was also categorized into a fear domain because it uniquely mentioned the trepidation of the victim. Finally, one response suggested shared 
Table 2.

Results of Chi Square Tests of Independence

\begin{tabular}{|lccccc|}
\hline & $\begin{array}{c}\text { Total } \\
n=365\end{array}$ & $\begin{array}{c}\text { History of } \\
\text { perpetration } \\
n=140\end{array}$ & $\begin{array}{c}\text { No history of } \\
\text { perpetration } \\
n=225\end{array}$ & $X^{2}$ & $p$ \\
\hline Lack of Consent & 233 & $83,59.29 \%$ & $150,66.67 \%$ & 2.04 & .15 \\
Sexual Activity & 154 & $47,33.57 \%$ & $107,47.56 \%$ & 6.92 & $<.01$ \\
Taken Advantage of & 216 & $79,56.43 \%$ & $137,50.89 \%$ & .71 & .40 \\
Sex & 176 & $74,52.86 \%$ & $102,45.33 \%$ & 1.96 & .16 \\
Unwanted & 98 & $44,31.43 \%$ & $54,24.00 \%$ & 1.41 & .12 \\
Harm to Victim & 23 & $13,9.29 \%$ & $10,4.44 \%$ & 3.43 & .06 \\
Gender/Sex-Specific & 20 & $13,9.29 \%$ & $7,3.11 \%$ & 6.35 & .01 \\
\hline
\end{tabular}

responsibility for rape because it indicated that both the victim and the perpetrator "should be held partially responsible for the accident."

\section{Exploratory Analysis: Differences be- tween Perpetrators and Non-Perpetra- tors}

Given that most participants provided definitions of rape that were generally consistent with the legal definition, we examined potential differences between individuals who reported SV perpetration over the course of their lifetime. We employed a chi-square test of independence to identify potential differences between the two categories because the groups were categorical. Using 2 (perpetrator/nonperpetrator) by 2 (absence/presence) chi square analysis to compare between domains with 20 or more responses ${ }^{6}$ (i.e., lack of consent, taken advantage of, sex, sexual activity, unwanted, harm to victim, gender/sex-specific), we identified a statistically significant difference between perpetrators and non-perpetrators in their use of the "sexual activity" domain $\left(X^{2}(I, N=365)=\right.$ $6.92, p=<.01$ ), as well as the gender/sex-

${ }^{6}$ Each test required at least 20 responses due to the 5 -
expected-per-cell assumption of chi square analysis, and specific domain $\left(X^{2}(I, N=365)=6.35, p=\right.$ $.01)$. Harm to victim trended toward significance $\left(X^{2}(I, N=365)=3.43, p=.06\right)$, with definitions from men with a history of SV perpetration more likely to be categorized into this domain but did not cross the $p<05$ threshold for statistical significance. No other tests achieved or trended toward statistical significance ( $p s=.15-.40$; see Table 2$)$. In other words, participants without a history of SV perpetration were more likely to recognize a broad definition of rape that included a wide range of sexual activities beyond penetration that constituted rape, and less likely to use gender/sex-specific language in their definitions, compared to men with lifetime experiences of SV perpetration. However, participants with and without a history of SV perpetration did not differ on five of the seven primary categories, suggesting that even men with a history of perpetration are generally just as knowledgeable about what constitutes rape as men without such history.

domains with at least 20 responses were least variant of the definitions provided. 


\section{Discussion}

In this study, we first used an inductive, consensual, qualitative methodology to explore college-aged men's conceptual definitions of "rape," given the predominance of rape myths and sexual scripts that may encourage men to perpetrate SV. Our findings suggest that most young men understand the basic components of what rape is, and their definitions could be categorized into nine primary domains - lack of consent, taken advantage of, sex, sexual activity, unwanted, gender/sex-specific, harm to victim, relationship, emotional response - and a miscellaneous domain. We found that very few men's definitions contained common rape myths (e.g., shared responsibility) or gendered sexual scripts (e.g., gender/sex-specific). Importantly, some referred to rape as a crime, and others had emotional reactions to the prompt. Many provided broad definitions of sexual activity (e.g., groping) that constituted rape, but others suggested that penetration (i.e., sex) was necessary for rape to occur, as per the legal definition of the term. Therefore, in general, the sexual scripts of the men sampled for this study show that collegeaged men are knowledgeable about the actions and behaviors that constitute rape, with some defining rape more broadly than the narrow, legal definition.

Notably, some men distinguished between nonconsensual sex/sexual activity and unwanted sex/sexual activity in their definitions. Given that lack of consent was the most common category for responses to this prompt, it stands to reason that college-aged men typically understand, in principle, that rape is usually nonconsensual. However, while the legal definition indicates that rape must be "nonconsensual", sexual activity can be unwanted but technically consensual (i.e., sexually compliant behavior; Carter et al., 2020; Impett \& Peplau, 2002), as well as wanted but non-consensual (e.g., Peterson \& Muehlenhard, 2007). The discrepancy between the number of men who indicated that rape was unwanted $(n=$ 98) compared to nonconsensual (lack of consent; $n=233$ ) suggests that there is cause to better- develop men's understanding of sexually compliant behaviors and the complex nature of consent. Specifically, results indicate that men may lack awareness of the myriad pressures that people, particularly women, must navigate during sexual encounters and the consequent role of sexual compliance in sexual activity.

Further, some respondents suggested that rape occurs in the context of relationships. This domain was rather broad, as it was unclear whether participants used the term "partner" to indicate a short-term or long-term sexual partner. However, the existence of this domain suggests that some men's foundational understanding of rape includes an acknowledgement of the likelihood of acquaintance and intimate partner rape. Additionally, while gendered definitions were variant in this study $(n=20)$, men who see rape as gender/sex-specific may not recognize themselves or their male peers as potential victims.

Our exploratory analyses suggest that both men with and without a history of SV perpetration can correctly identify the primary components of rape, and responses generally did not differ between groups. Specifically, groups did not differ in how often they provided responses that included lack of consent, taken advantage of, sex, unwanted, or harm to victim (though harm to victim was slightly more common among men with a history of SV perpetration). However, in some ways, men with a lifetime history of SV perpetration may perceive rape more narrowly than do men without this history. Specifically, those who had committed SV in the past provided definitions of rape that were less likely to include behaviors outside of penetration that constitute rape. While technically correct based on the 2012 definition of rape, the expanded 2012 definition focuses exclusively on penetration and is influenced by a cultural acceptance of sexually violent behaviors (i.e., "rape culture"; Burt, 1980; Johnson \& Johnson, 2017). This definition fails to capture myriad routine sexual violence experienced by both women (Papp \& McClelland, 2020) and men (Stemple \& Meyer, 
20I4) that can have a lasting detrimental effect on survivors.

Similarly, men with a history of SV perpetration were more likely to define rape as gender/sex-specific, suggesting that men were the perpetrators and women the victims of rape. They were also marginally more likely to list as harm as a requirement for rape to have occurred. However, given the small number of men who provided gendered definitions, this finding should be interpreted with caution. Put another way, the rape scripts of men with a history of SV perpetration were more closely aligned with narrow, gendered scripts, requiring visible/physical harm compared to men without a history of SV perpetration.

One potential explanation for this pattern of results is that perpetrators of SV use narrower definitions to normalize and justify their own sexually violent behaviors, potentially as a way to resolve the cognitive dissonance they may feel as a result of their transgression (Wegner et al., 20I5). Given that we used a wide definition of SV perpetration, including both physical and psychological sexual violence, it is possible these men provided specific, narrow definitions to distance their own behaviors from "rape." This is consistent with past literature in which men with histories of SV perpetration used common cultural scripts and myths to normalize their behaviors (Beech et al., 2006; Hipp et al., 2017). When rape is narrowly defined, behaviors that do not fit within this specific definition may be regarded as less harmful and more normative.

\section{Practice Implications}

Our findings indicate that most men can correctly define rape and recognize its impact, suggesting that most young men do, in fact, know what rape is. The variant findings, especially regarding gender and relationships, point to the need for universal comprehensive, researchdriven sexual education, which may reduce SV on college campuses (Banyard \& Potter, 2018; Jouriles et al., 2018; Santelli et al., 2018). We echo Orchowski et al. (2020) in recommending that sexual violence interventionists consider addressing the contexts and cultures in which rape is likely and encourage men to be hypervigilant in these situations (e.g., high-risk situations with social pressure and binge alcohol use). Programs should address the topics of sociocultural pressures, masculine norms, information about the legal ramifications of sexual violence, and bystander intervention information (Orchowski et al., 2020), and educate participants on the role of sexual compliance in sexual interactions. These sexual education programs should be forthright about the gender demographics of victims and perpetrators while remaining explicitly clear that people of all genders may experience sexual violence.

Some theorists have also proposed that instances of SV may arise as a result of overreliance on sexual scripts and resultant miscommunication between partners (Kitzinger \& Frith, 1999). However, our findings do not support the idea that sexual scripts and rape myths are embedded in men's foundational understandings of rape, and most research suggests that miscommunication does not drive SV (Beres, 2009; Beres et al., 2014; O'Byrne et al., 2008). Therefore, rather than belaboring the point about the basic definitions of "consent," "rape," or "sexual violence," we encourage sexual education programs to discuss process-based models of consent to ensure that communication about sexual desire and consent is understood clearly (Glace et al., 2020) and to discuss situations and contexts where rape is more likely to occur (e.g., in the presence of alcohol; Abbey, 2002; Lorenz \& Ullman, 2016).

However, given that SV continues to be a pervasive issue, mere awareness of SV is not sufficient for reducing its likelihood (see also Anderson \& Whiston, 2005). More research is needed to understand what further interventions and consequences-including changes to the legal system - are needed to prevent and deter men from engaging in sexually violent behav- 
iors. This can include the development of programs that encourage men to simultaneously support other men's engagement in sexually healthy, consensual behaviors while challenging each other's justifications for or denial of sexual violence. Such programs are acutely needed in subgroups or cultures where the minimization of sexual violence and the dehumanization of victims is especially pronounced (e.g., forensic populations to reduce recidivism, Greek culture on college campuses).

On a broader level, it is important that all people are empowered with the tools, skills, and resources to competently and confidently initiate, consent to, and refuse sexual activity. Our results suggest that men's understanding about the definition of rape is insufficient for preventing sexual violence. We encourage integrating discussions of sexual ethics (e.g," Carmody, 2005) into these trainings to encourage men to accept responsibility for their sexual behaviors and act in accordance with their knowledge and personal, moral values. Further, it is not women's responsibility to stop sexual violence from happening to them. However, research suggests that sexual assault resistance interventions can reduce women's likelihood of victimization by empowering them to detect risks, resist attempts, and defend themselves against sexual aggression (Senn et al., 2020). Therefore, while women wait for cultural change to happen, they may wish to consider participating in some form of self-defense training, such as the Enhanced Access, Acknowledge, Act program, which has been shown to reduce women's likelihood of experiencing rape both at one and two year follow-up (Senn et al., 2015, 2017).

\section{Limitations and Future Directions}

We acknowledge that no study is without its limitations. Importantly, given the postpositivist nature of CQR-M, it is possible that other researchers would have identified different domains or classified responses differently than this research team did. In fact, in other studies of college students' definitions of rape (Haugen et al., 2018), the research team identified a different pattern of themes from their mixed-gender sample. It is also possible that results would be different with a more racially diverse set of participants. While our sample was representative of the university as a whole, were this study conducted at a study with a more racially diverse student body, it is possible that the dataset may have been somewhat different. Further, when identifying men with a history of SV for our analyses, we used a broad definition of sexual violence perpetration, including both physical and psychological SV. However, it is possible results may vary depending on the type of SV perpetrated, and we support future work on this important topic. Researchers may wish to explore the definitions of particular subgroups of college-aged men (e.g., athletes, men who are affiliated with Greek life), and we encourage developmental research on rape myths to assess key ages for education and intervention. We encourage future researchers to consider how this line of research can be continued and expanded upon.

\section{Conclusion}

Sexual education curricula need to include discussions about what rape is and is not, its function, and its impact. However, given that men generally understand the basic definition of rape, we encourage educators to channel limited time and resources into teaching about the broad continuum of sexual violence, its relationship with substance use, situational and sociocultural motivators of rape, and the influence of gender norms, particularly in programs involving men with histories of SV perpetration. We encourage the continued examination of men's attitudes and experiences regarding sexual violence to continue to fill this critical gap in the literature.

\section{Acknowledgements}

The authors would like to thank the research assistants at the Sexual Violence Prevention Research Lab at the University of North Dakota, whose dedication to this project made this study possible. 


\section{References}

Abbey, A. (2002). Alcohol-related sexual assault: A common problem among college students. Journal of Studies on Alcohol. Supplement, 14, II8-128. https://doi.org//0.15288/jsas.2002.s I4.I I8

Anderson, L. A., \& Whiston, S. C. (2005). Sexual assault education programs: A meta-analytic examination of their effectiveness. Psychology of Women Quarterly, 29(4), 374-388. https://doi.org/ I0. I I I I/j. I 47I 6402.2005.00237.x

Anderson, R. E., Cahil, S. P., \& Delahanty, D. L. (2017). Initial evidence for the reliability and validity of the Sexual Experiences Survey Short Form (SES-SFP) in college men. Journal of Aggression, Maltreatment, and Trauma, 26(6), 626-643. https://doi.org/I0.1080/1092677I.2017.133 0296

Anderson, R. E., Silver, K. E., Ciampaglia, A. M., Vitale, A. M., \& Delahanty, D. L. (20/9). The frequency of sexual perpetration in college men: A systematic review of reported prevalence rates from 2000 to 2017. Trauma, Violence, \& Abuse, I-15. https://doi.org/10.1 177/1524838019860619

Aosved, A. C., \& Long, P. J. (2006). Co-occurrence of rape myth acceptance, sexism, racism, homophobia, ageism, classism, and religious intolerance. Sex Roles, 55, 48I-492. https://doi.org/I0.1007/s I I 199-006-9101-4

Aosved, A. C., Long, P. J., \& Voller, E. K. (20II). Sexual revictimization and adjustment in college men. Psychology of Men \& Masculinity, I2(3), 285-296. https://doi.org/10.1037/a0020828

Aronowitz, T., Lambert, C. A., \& Davidoff, S. (20I2). The role of rape myth acceptance in the social norms regarding sexual behavior among college men. Journal of Community Health Nursing, 29(3), 173-182. https://doi.org/I0.1080/073700I6.20I2.697 852
Banyard, V. L., \& Potter, S. J. (20|8). Envisioning comprehensive sexual assault prevention for college campuses. In C. B Travis, J. W. White, A. Rutherford, W. S. Williams, S. L. Cook, \& K. F. Wyche (Eds.), APA handbooks in psychology $\AA^{\circledR}$. APA handbook of the psychology of women: Perspectives on women's private and public lives (p. 235-25I). American Psychological

Association.

https://doi.org// 0.1037/0000060-013

Barone, R. P., Wolgemuth, J. R., \& Linder, C. (2007). Preventing sexual assault through engaging college men. Journal of College Student Development, 48(5), 585-594. https://doi.org// 0.1353/csd.2007.0045

Beech, A. R., Ward, T., \& Fisher, D. (2006). The identification of sexual and violent motivations in men who assault women: Implications for treatment. Journal of Interpersonal $V_{i}$ olence, $\quad 2 I(12), \quad$ 1635-1653. https://doi.org// $0.1177 / 0886260506294242$

Beres, M. (2009). Sexual miscommunication? Untangling assumptions about sexual communication between casual sexual partners. Culture, Health, \& Sexuality: An International Journal for Research, Intervention, and Care, I2(I), I-I4. https://doi.org//0.1080//369/05090307522 6

Beres, M. A. (2014). Points of convergence: Introducing sexual scripting theory to discourse approaches to the study of sexuality. Sexuality \& Culture, 18, 76-88. https://doi.org/I0.1007/s I2I 19-0|3-9|76-3

Beres, M. A., Senn, C. Y., \& McCaw, J. (2014). Navigating ambivalence: How heterosexual young adults make sense of desire differences. The Journal of Sex Research, 5 I (7), 765776.

https://doi.org//0.1080/00224499.2013.792 327

Berntson, M. A., Hoffman, K. L., \& Luff, T. L. (20I3). College as context: Influences on in- 
terpersonal sexual scripts. Sexuality \& Culture, I8, I49-165. https://doi.org/| 0.1007/s I 2 I I9-0 I3-9 I80-7

Bowleg, L., Burkholder, G. J., Noar, S.M., Teti, M., Malebranche, D.J., Tschann, J.M. (20I3). Sexual scripts and sexual risk behaviors among Black heterosexual men: Development of the Sexual Scripts Scale. Archives of Sexual Behavior, 44(3):639-54. https://doi.org/10.1007/s10508-013-0193-y

Bridges, A. J., Sun, C. F., Ezzell, M. B., \& Johnson, J. (20I6). Sexual Scripts and the sexual behavior of men and women who use pornography. Sexualization, Media, \& Society. https://doi.org/I0.I I 77/23746238I6668275

Burt, M. R. (1980). Cultural myths and supports for rape. Journal of Personality and Social Psychology, 38, 217-230. https://doi.org//0.1037/0022-35 |4.38.2.217

Byers, S. E. (1996). How well does the traditional sexual script explain sexual coercion? Review of a program of research. Journal of Psychology \& Human Sexuality 8(I), 7-25

Carpenter, L. M. (1998). From girls into women: Scripts for sexuality and romance in seventeen magazine, 1974-1994. The Journal of Sex Research, 35(2), I58-168. https://doi.org/ I0.1080/0022449980955192 9

Carter, A., Newman, C., de Visser, R., Yeung, A., Rissel, C., Grulich, A., Haire, B., Bateson, D., Vaughn, C., McGeechan, K., Donovan, B., Richters, J., \& Guy, R. (2020). Unwanted sex due to intoxication in Australians aged 16-69 years. The Journal of Sex Research. https://doi.org// 0.1080/00224499.2020.182 9530

Chapleau, K. M., Oswald, D. L., \& Russell, B. L. (2007). How ambivalent sexism toward women and men support rape myth acceptance. Sex Roles, 57, |3|-|36. https://doi.org/I0.1007/s I I I99-007-9196-2

Eaton, A. A., \& Rose, S. (20II). Has dating become more egalitarian? A 35-year review using Sex Roles. Sex Roles, 64( I I-I 2), 843-862. https://doi.org/ I0.1007/s I I 199-0 I I-9957-9
Eaton, A. A., Rose, S. M., Interligi, C., \& Fernandez, K., \& McHugh, M. (20I6). Gender and ethnicity in dating, and hanging out, and hooking up: Sexual scripts among Hispanic and white young adults. The Journal of Sex Research, 53(7), 788-804. https://doi.org/ I0.1080/00224499.20I5.106 5954

Edwards, K. M., Turchik, J. A., Dardis, C. M., Reynolds, N., \& Gidycz, C. A. (20II). Rape myths: History, individual and institutionallevel presence, and implications for change. Sex Roles, 65, 761-773. https://doi.org/ I0.1007/s I I 99-0 I I-9943-2

Edwards, S. R., Bradshaw, K. A., \& Hinsz, V. B. (20I4). Denying rape but endorsing forceful intercourse: Exploring differences among responders. Violence and Gender, I(4). https://doi.org/l 0.1089/vio.2014.0022

Flood, M. (2006). Changing men: Best practice in sexual violence education. Women Against Violence: An Australian Feminist Journal.

Frith, H. (20I3). Sexual scripts, sexual refusals, and rape. In M. Hovarth and J. Brown (Eds.) Rape: Challenging contemporary thinking. Routledge.

Frith, H., \& Kitzinger, C. (200I). Reformulating sexual script theory: Developing a discursive psychology of sexual negotiation. Theory \& Psychology, II(2), 209-232. https://doi.org/ I 0. I I 77/095935430 I I I 2004

Gagnon, J. H., \& Simon, W. (1973). Sexual Conduct: The Social Sources of Human Sexuality. Aldine, Chicago

Griswold, S. R., Neal Kimball, C., \& Alayan, A. J. (2020). Males' stories of unwanted sexual experiences: A qualitative analysis. Psychology of Men \& Masculinities, 21 (2), 298-308. https://doi.org/10.1037/men0000247

Haugen, A. D., Rieck, S. M., Salter, P. S., \& Phillips, N. L. (2018). What makes it rape? A lay theories approach to defining rape among college students. Basic and Applied Social Psychology, 40(I), 18-35. https://doi.org/10.1080/01973533.2017.139 809l 
Hayes, R. M., Abbott, R. L., \& Cook, S. (2016). It's her fault: Student acceptance of rape myths on two college campuses. Violence Against Women, 22(13), I540-1555. https://doi.org/I0.1 I77/107780I216630I47

Hill, C. E. (20I2). Consensual Qualitative Research: A practical resource for investigating social science phenomena. American Psychological Association.

Hill, C. E., Knox, S., Thompson, B. J., Williams, E. N., Hess, S. A., \& Ladany, N. (2005). Consensual qualitative research: An update. Journal of Counseling Psychology, 52(2), 196$205 . \quad$ https://doi.org//0.1037/00220167.52.2.196

Hipp, T. N., Bellis, A. L., Goodnight, B. L., Brennan, C. L., Swartout, K. M., \& Cook, S. L. (2017). Justifying sexual assault: Anonymous perpetrators speak out online. Psychology of Violence, $\quad 7(1), \quad 82-90$. https://doi.org//0.1037/a0039998

Hoppe, T. (20I I). Circuits of power, circuits of pleasure: Sexual scripting in gay men's bottom narratives. Sexualities, 14(2), 193-217. https://doi.org//0.1177//3634607/1399033

Impett, E. A., \& Peplau, L. A. (2002). Why some women consent to unwanted sex with a dating partner: Insights from attachment theory. Psychology of Women Quarterly, 26(4), 360-370. https://doi.org//0.1 I I I/I47I6402.t0 I-I-00075

Johnson, N. L., \& Johnson, D. M. (2017). An empirical exploration into the measurement of rape culture. Journal of Interpersonal Violence. Published online first. https://doi.org/I0.I I77/08862605 I 7732347

Johnson, S. M., \& Murphy, M. J., \& Gidycz, C. A. (2017). Reliability and validity of the Sexual Experiences Survey - Short Form Victimization and Perpetration. Violence and Victims, 32(I), 78-92. https://doi.org//0.1891/08866708.VV-D-15-00II0

Jouriles, E. N., Krauss, A., Vu, N. L., Vanyard, V. L., \& McDonald, R. (2018). Bystander programs addressing sexual violence on college campuses: A systematic review and metaanalysis of program outcomes and delivery methods. Journal of American College Health, 66(6), 457-466. https://doi.org/I0.1080/0744848I.2018.143 1906

Kim, J. L., Sorsoli, C. L., Collins, K., Zybergold, B. A., Schooler, D., \& Tolman, D. L. (2007). From sex to sexuality: Exposing the heterosexual script on primetime network television. The Journal of Sex Research, 44(2), I45157.

https://doi.org/I0.1080/0022449070I26366 0

Kitzinger, C., \& Frith, H. (1999). Just say no? The use of conversation analysis in developing a feminist perspective on sexual refusal. Discourse \& Society, I0(3), 293-316. https://doi.org/I0.1 I 77/0957926599010003 002

Koss, M. P. (1993). Rape: Scope, impact, interventions, and public policy responses. American Psychologist, 48(10), 1062-1069. https://doi.org/ $0.1037 / 0003-$ 066X.48.10.1062

Koss, M. P. (1998). Hidden rape: Sexual aggression and victimization in a national sample of students in higher education. In M. E. Odem \& J. Clay-Warner (Eds.), Worlds of women, No. 3. Confronting rape and sexual assault (p. 5I-69). SR Books/Scholarly Resources. (Reprinted from A. W. Burgess (Ed.), Rape and Sexual Assault II, New York: Garland Publishing, 1988, pp. 3-25)

Koss, M. P., Abbey, A., Campbell, R., Cook, S., Norris, J., \& Testa, M., \& ... White, J. (2007). Revising the SES: A collaborative process to improve assessment of sexual aggression and victimization. Psychology of Women Quarterly, 3 I (4), 357-370. https://doi.org/I0.1 I I I/j. I47 I6402.2007.00385.x

Krebs, C. P., Lindquist, C. H., Warner, T. D., Fisher, B. S., \& Martin, S. L. (2007). The campus sexual assault (CSA) study final 
report. Washington, DC: National Institute of Justice.

Laner, M. R., \& Ventrone, N. A. (2000). Dating scripts revisited. Journal of Family Issues, $2 I(4)$ 488-500. https://doi.org/ I0.1 I 77/01925 I 3000210040 04

Lorenz, K., \& Ullman, S. E. (20I6). Alcohol and sexual assault victimization: Research findings and future directions. Aggression and Violent Behavior, 31, 82-94. https://doi.org/ I0.10 I6/j.avb.2016.08.00 I

Lonsway, K. A., \& Fitzgerald, L. F. (1995). Attitudinal antecedents of rape myth acceptance: A theoretical and empirical reexamination. Journal of Personality and Social Psychology, 68(4), 704-7II. https://doi.org/| 0.1037/0022-35|4.68.4.704

Martinez, T., Wiersma-Mosley, J. D., Jozkowski, K. N., \& Becnel, J. (20I8). "Good Guys Don't Rape": Greek and Non-Greek College Student Perpetrator Rape Myths. Behavioral sciences (Basel, Switzerland), 8(7), 60. https://doi.org// 0.3390/bs8070060

McMahon, S., \& Farmer, G. L. (20II). An updated measure for assessing subtle rape myths. Social Work Research, 35(2), 7I-8I.

Morrison, D. M., Masters, N. T., Wells, E. A., Casey, E., Beadnell, B., \& Hoppe, M. J. (20I5). "He enjoys giving her pleasure": diversity and complexity in young men's sexual scripts. Archives of Sexual Behavior, 44(3), 655-668. https://doi.org/ 10.1007/s I0508-014-0354-7

Muehlenhard, C. L., Peterson, Z. D., Humphreys, T. P., \& Jozkowski, K. N. (20I7). Evaluating the one-in-five statistic: Women's risk of sexual assault while in college. The Journal of Sex Research, 54(4-5), 549-576. https://doi.org/ I0.1080/00224499.2017.129 5014

Muehlenhard, C. L., Powch, I. G., Phelps, J. L., \& Guisti, L. M. (1992). Definitions of rape: Scientific and political implications. Journal of Social Issues, 48(I), 23-44.

https://doi.org/10.1 I I I/j. I5404560.1992.tb0II55.x
O'Connor, J., Cusano, J., McMahon, S., \& Draper, J. (2018). Students' articulation of subtle rape myths surrounding campus sexual assault. Journal of College Student Development, 59(4), 439-455. https://doi.org/10.1353/csd.2018.004 I

Orchowski, L. M., Edwards, K. M., Hollander, J. A., Banyard, V. L., Senn, C. Y., \& Gidycz, C. A. (2020). Integrating sexual assault resistance, bystander, and men's social norms strategies to prevent sexual violence on college campuses: A call to action. Trauma, Violence, \& Abuse, 2l(4), 8II-827. https://doi.org//0.1I77//524838018789/53

Papp, L. J., \& McClelland, S. I. (2020). Too common to count? "Mild" sexual assault and aggression among US college women. The Journal of Sex Research,. Published online first. https://doi.org/ I0.1080/00224499.2020.177 8620

Peterson, Z. D., \& Muehlenhard, C. L. (2007). Conceptualizing the "wantedness of women's consensual and nonconsensual sexual experiences: Implications for how women label their experiences with rape. Journal of Sex Research, 44(I), 72-88. https://doi.org/ I0.1080/0022449070933679 4

Pham, J. M. (20I6). The limits of heteronormative sexual scripting: College student development of individual sexual scripts and descriptions of lesbian sexual behavior. Frontiers in Sociology, https://doi.org//0.3389/fsoc.20/6.00007

Rodgers, K. B., \& Hust, S. J. T. (2018). Sexual objectification in music videos and acceptance of potentially offensive sexual behaviors. Psychology of Popular Media Culture, 7(4), 4I3428. https://doi.org//0.1037/ppm0000142

Ryan, K. M. (20II). The relationship between rape myths and sexual scripts: The social construction of rape. Sex Roles, 65, 774-782. https://doi.org/ I0.1007/s I I | 99-0 I I-0033-2

Santelli, J. S., Grilo, S. A., Choo, T. -H., Diaz, G., Walsh, K., Wall, M., Hirsch, J. S., Wilson, P. A., Gilbert, L., Khan, S., \& Mellins, C. A. (20I8). Does sex education before college 
protect students from sexual assault in college? PloS One. https://doi.org//0.137//journal.pone.020595 I

Senn, C. Y., Eliasziw, M., Barata, P. C., Thurston, W. E., Newby-Clark, I. R., Radtke, H. L., \& Hobden, K. L. (20I5). Efficacy of a sexual assault resistance education program for university women. New England Journal of Medicine, 372(4), 2326-2335. https://doi.org/ I0. I056/NEJMsa I 4 I I I 3 |

Senn, C. Y., Eliasziw, M., Hobden, K. L., Barata, P. C., Radtke, H. L., Thurston, W. E., \& Newby-Clark, I. R. (2020). Testing a model of how a sexual assault resistance education program for women reduces sexual assaults. Psychology of Women Quarterly. Published online first. https://doi.org/ I0.I I 77/036 I68432096256 I

Senn, C. Y., Eliasziw, M., Hobden, K. L., NewbyClark, I. R., Barata, P. C., Radtke, H. L., \& Thurston, W. E. (2017). Secondary and 2year outcomes of a sexual assault resistance program for university women. Psychology of Women Quarterly, 4I(2), I47-I62. https://doi.org/I0.1 I77/03616843176901 I9

Simon, W., \& Gagnon, J. H. (2003). Sexual scripts: Origins, influences, and changes. Qualitative Sociology, 26, 49l-497. https://doi.org/ I0.1023/B:QUAS.000000505 3.99846.e5

Snyder, C. R., \& Higgins, R. L. (1988). Excuses: Their effective role in the negotiation of reality. Psychological Bulletin, 104(I), 23-35. https://doi.org/ I0.1037/0033-2909.104.I.23

Spangler, P. T., Liu, J., \& Hill, C. (20I2). Consensual qualitative research for simple data: An introduction to CQR-M. In C. E. Hill (Ed.) Consensual qualitative research: Practical resource for investigating social science phenomena (p. 269-283). American Psychological Association.

Stemple, L., \& Meyer, I. H. (20/4). The sexual victimization of men in America: new data challenge old assumptions. American Journal of Public Health, 104(6), el9-e26. https://doi.org/10.2105/AJPH.2014.301946

Strang, E., \& Peterson, Z. D. (2017). Unintentional misreporting on self-report measures of sexually aggressive behavior: An interview study. The Journal of Sex Research, 54(8), 97I983.

https://doi.org/ I0.1080/00224499.2017.130 4519

Strang, E., \& Peterson, Z. D. (2020). Use of a bogus pipeline to detect men's underreporting of sexually aggressive behavior. Journal of Interpersonal Violence, 35(I-2), 208-232. https://doi.org/ I0.1 I 77/08862605 I668II 57

Straus, M., Hamby, S., Boney-McCoy, S., \& Sugarman, D. B. (1996). The Revised Conflict Tactics Scales (CTS2): Development and preliminary psychometric data. Journal of Family Issues, I 7(3), 283-3 I6. https://doi.org/ I0.1I77/01925139601700300 I

Suarez, E., \& Gadalla, T. M. (2010). Stop blaming the victim: A meta-analysis on rape myths. Journal of Interpersonal Violence, 25(I I), 20102035. https://doi.org/ I 0. I I 77/0886260509354503

United States Department of Justice. (20I2). Updated definition of rape. https://www.justice.gov/archives/opa/blog/updated-definition-rape

Warkentin, J. B., \& Gidycz, C. A. (2007). The use and acceptance of sexually aggressive tactics in college men. Journal of Interpersonal Violence, 22(7), 829-850. https://doi.org//0.1 I77/0886260507301793

Williams, E. N., \& Hill, C. E. (20I2). Establishing trustworthiness in consensual qualitative research studies. In C. E. Hill (Ed.), Consensual qualitative research: $A$ resource for investigating social science phenomena (pp. 175-186). American Psychological Association.

Ybarra, M. L., \& Mitchell, K. J. (20I3). Prevalence rates of male and female sexual violence perpetrators in a national sample of adolescents. JAMA Pediatrics, I67( I2), I I 25-I I 34. 
https://doi.org/10.100 I/jamapediat-

rics.2013.2629

Yeh, C. J., \& Inman, A. G. (2007). Qualitative data analysis and interpretation in counseling psychology: Strategies for best practices. The
Counseling Psychologist, 35, 369-403. https://doi.org/ I 0. I I 77/00 I I 000006292596 